\title{
GLIA ARE A UNIQUE SUBSTRATE FOR THE IN VITRO GROWTH OF CENTRAL NERVOUS SYSTEM NEURONS ${ }^{1}$
}

\author{
MARK NOBLE,,, 2 JUIN FOK-SEANG, $\ddagger$ AND JIM COHEN $\ddagger$ \\ * Department of Clinical Neurology, Institute of Neurology, London WC1N 3BG, England and $\$$ Medical Research Council \\ Neuroimmunology Project, Department of Zoology, University College London, London WC1E 6BT, England
}

Received July 6, 1983; Revised November 29, 1983; Accepted February 7, 1984

\begin{abstract}
We have examined the consequences of surface interactions with glial and nonglial cells on the in vitro growth of CNS neurons. When cerebellar or spinal cord cells were plated onto monolayers highly enriched in cortical astrocytes or sciatic nerve Schwann cells, neurons generally grew as single cells and showed relatively little tendency to aggregate. Similarly, neurites showed little tendency to fasciculate. In contrast, when plated onto fibroblast, heart muscle-fibroblast, or astrocyte-free meningeal monolayers, neurons rapidly aggregated, and neurite outgrowth was primarily in large fascicles. There were no glia detectable in the majority of aggregates or fascicles, suggesting that aggregation and fasciculation were due to interactions between neurons. Neurite outgrowth over $24 \mathrm{hr}$ was also greater on astrocytes than on nonglia.

Whether or not aggregation and fasciculation occurred was due to surface properties of the glial and nonglial cells. When neurons were added to astrocyte and nonglial monolayers growing in medium conditioned by a large excess of co-cultured nonglia or astrocytes, respectively, the pattern of neuronal growth was determined by the type of monolayer with which the neurons were in contact. Moreover, the initial growth of neurons on heat-killed astrocytes was indistinguishable from growth on living astrocytes.

The pattern of neuronal growth on these different monolayers suggests that neurons are more adherent to glia than to other neurons but are more adherent to other neurons than to nonglia. Such an adherence hierarchy could explain the consistent finding of an apposition of neurons to glial surfaces during neuronal migration and axon outgrowth. Our findings also suggest that the interaction of axons with the non-neuronal milieu through which they grow may play an important role in regulating fasciculation, a process which has generally been treated as due primarily to axonaxon interactions.
\end{abstract}

A striking architectural feature of the development of the central nervous system is the frequency with which varied aspects of neuronal movement occur in close apposition with glial cells. Migration of many, and possibly all, postmitotic neurons to their final positions occurs along the processes of radial glia (Levitt and Rakic, 1980), and axon outgrowth in such structures as

\footnotetext{
${ }^{1}$ It is a pleasure to acknowledge the warm and stimulating atmosphere of the Medical Research Council Neuroimmunology Project, the many useful discussions with Martin Raff and other members of the group, and also the exciting and critical discussions with Jerry Silver, Michael Katz, Ray Lasek, and John Holley of Case Western Reserve University. We thank J. Silver, M. Katz, M. Raff, Justin Fallon, and Richard Hynes for their helpful comments on the manuscript. M. N. is supported by a Medical Research Council Project grant, and J. F. -S. and J. C. are supported by a Medical Research Council programme grant.

${ }^{2}$ To whom correspondence should be addressed.
}

optic nerve and corpus callosum has been shown to occur along pathways of primitive glia (Silver and Sapiro, 1981; Silver et al., 1982). The regularity with which neuronal movements are associated with glial structures has led many investigators to propose that the glia play a major role in determining the structure of the central nervous system.

A second characteristic architectural feature of development in the CNS is the bundling of individual growing axons into fascicles. Because most fascicles are initially devoid of glial cells, the process of fasciculation is generally thought to be mediated by neuron-neuron interactions, with little or no contribution from non-neuronal cells. The molecular basis of fasciculation seems at least in part to involve neuronal cell surface proteins (Rutishauser et al., 1978; Jorgenson et al., 1980).

In the course of our studies on glial cell development and function, we have found that astrocytes and 
Schwann cells can profoundly influence the hehavior of CNS neurons in vitro. These glial-neuronal interactions appear to be mediated by glial cell surface properties which make these cells a particularly adherent substrate for axonal growth. Such adherence interactions may account, on a cellular level, for many of the observations on the structuring of neuronal growth during development.

\section{Materials and Methods}

Monolayer cultures. Highly enriched astrocytes were prepared by a modification of the procedure of McCarthy and de Vellis (1980). Two $\times 10^{7}$ cells dissociated from the cerebral cortex of 2-day rats were cultured for 9 to 10 days in Falcon tissue culture flasks $\left(75 \mathrm{~cm}^{2}\right.$ surface area) in Dulbecco's Modified Eagle's Medium (DMEM) plus $15 \%$ fetal calf serum (FCS), $2 \mathrm{~mm}$ glutamine, $6 \mathrm{gm} /$ liter of glucose, and $25 \mu \mathrm{g} / \mathrm{ml}$ of gentamicin. Flasks were then shaken overnight at $37^{\circ} \mathrm{C}$ on a rotary platform. Using cell type-specific antibodies (see below) to identify cell types, the remaining adherent cells contained no neurons, oligodendrocytes, or macrophages and were 85 to $95 \%$ astrocytes. The astrocytes were all of the type I variety found in cultures of both grey and white matter; the overnight shaking also removed type II (fibrous) astrocytes, an astrocyte subpopulation unique to white matter (Raff et al., 1983).

Astrocytes were then removed from flasks by incubating with $0.025 \%$ trypsin in $\mathrm{Ca}^{++}, \mathrm{Mg}^{++}$-free DMEM, centrifuged, diluted in growth medium to one-third of their original density, and replated in culture flasks. The cells were allowed to adhere and grow overnight and were then pulsed with $2 \times 10^{-5} \mu \mathrm{M}$ cytosine arabinoside (AraC) for 2 days, fed with fresh medium, and after $24 \mathrm{hr}$ pulsed a second time with $\mathrm{AraC}$ for 2 days. This treatment produced cultures which were reproducibly $>95 \%$ astrocytes, as judged by indirect immunofluorescence with rabbit antiserum against glial fibrillary acidic protein (GFAP) (Bignami et al., 1972).

For use as support layers for neurons or in conditioned medium experiments, these enriched secondary astrocytes were plated directly onto poly-L-lysine (PLL)coated glass coverslips (Chance No. 1, $13 \mathrm{~mm}$ diameter) at 40,000 cells/coverslip or onto PLL-coated 60 -mm tissue culture Petri dishes (Falcon) at 400,000 cells/dish.

Fibroblasts from the dorsal skin of 1- to 2-day rats were prepared by incubating minced skin in HEPESbuffered (20 mM) Minimum Essential Medium (MEM$\mathrm{H})$ plus $0.25 \%$ collagenase (Collaborative Research) for $60 \mathrm{~min}$ at $37^{\circ} \mathrm{C}$, followed by addition of an equal volume of $0.25 \%$ trypsin and further incubation for $30 \mathrm{~min}$ at $37^{\circ} \mathrm{C}$. Tissue chunks were dissociated by repetitive trituration through a wide-bore pipette. Fibroblasts were grown in tissue culture flasks prior to plating on PLLcoated coverslips or in 60 -mm Petri dishes.

Astrocyte-free meningeal cultures were prepared by incubating leptomeninges from 2-day rat cerebral cortex in MEM-H plus $0.25 \%$ collagenase and $0.125 \%$ trypsin at $37^{\circ} \mathrm{C}$ for $30 \mathrm{~min}$, and dissociating by repetitive trituration through a wide-bore pipette. Meningeal cells were grown to confluence in tissue culture flasks, removed with trypsin and $\mathrm{Ca}^{++}, \mathrm{Mg}^{++}$-free DMEM, centrifuged, diluted in growth medium to one-fifth of their original density, replated, and grown again to confluence before replating onto polylysine-coated glass coverslips. The cells in these cultures were uniformly $\mathrm{GFAP}^{-}$and were positive for labeling with rabbit antifibronectin antiserum. For some experiments we also used primary meningeal cultures which contained 10 to $20 \% \mathrm{GFAP}^{+}$cells.

Cardiac muscle fibroblast cultures were grown by incubating minced hearts from newborn rats for $60 \mathrm{~min}$ at $37^{\circ} \mathrm{C}$ in MEM-H plus $0.25 \%$ collagenase, followed by addition of an equal volume of $0.25 \%$ trypsin for $30 \mathrm{~min}$ at $37^{\circ} \mathrm{C}$. The supernatant was then replaced with a fresh solution of trypsin and collagenase, and tissue was incubated a final $15 \mathrm{~min}$ at $37^{\circ} \mathrm{C}$, washed twice with $\mathrm{Ca}^{++}$, $\mathrm{Mg}^{++}$-free DMEM plus soybean trypsin inhibitor (SBTI, $0.52 \mathrm{mg} / \mathrm{ml}$; Sigma), DNAse (0.04 mg/ml; Sigma), and bovine serum albumin (BSA, $3 \mathrm{mg} / \mathrm{ml}$; Sigma), and dissociated by repetitive trituration in a wide-bore pipette. Heart cells were plated onto collagen-coated coverslips at 1 heart/12 coverslips. Only cultures containing large areas of twitching muscle were used as support monolayers.

Enriched Schwann cell cultures were prepared from sciatic nerves from 5- to 7-day old rats, which were minced and incubated as for skin fibroblasts. Sciatic nerve cells were plated into tissue culture flasks, allowed to settle overnight, and pulsed with AraC for $24 \mathrm{hr}$. One hundred fifty thousand cells were then plated onto collagen-coated coverslips, or in a 50- $\mu$ l drop in the center of a collagen-coated $30-\mathrm{mm}$ Petri dish, allowed to grow overnight, pulsed again with AraC for $24 \mathrm{hr}$, and then maintained until use in DMEM plus 15\% FCS, 2 mM glutamine, $6 \mathrm{mg} / \mathrm{ml}$ of glucose, $25 \mu \mathrm{g} / \mathrm{ml}$ of gentamicin, and $50 \mu / \mathrm{ml}$ of pituitary extract (Raff et al., 1978a). At the time of use, Schwann cell cultures contained less than $10 \%$ firoblasts, as identified by labeling with antiThy 1 antiserum (Brockes et al., 1977).

All support monolayers were grown to confluence and prior to use were irradiated with $2000 \mathrm{rad}$ to prevent further cell division.

Cerebellum and spinal cord cell suspensions. Cerebella from 7-day-old rats were dissected free of meninges, minced, and incubated at $37^{\circ} \mathrm{C}$ for $15 \mathrm{~min}$ in $\mathrm{Ca}^{++}, \mathrm{Mg}^{++}$free Earle's balanced salts (BSS) plus $0.025 \%$ trypsin, washed with BSS, resuspended in BSS plus SBTI $(0.025 \%)$ and DNAse $(50 \mu \mathrm{g} / \mathrm{ml})$, and dissociated by repetitive trituration. Undisrupted chunks of tissue were allowed to settle at $1 \times g$ to the botton of the incubation tube, and the dissociated cells in the supernatant were centrifuged at $500 \times \mathrm{g}$ for $10 \mathrm{~min}$, resuspended in DMEM, and counted in a hemocytometer. The resulting single cell suspensions were 90 to $95 \%$ viable by trypan blue exclusion.

Spinal cords from 14-day-old rat embryos were dissected free of meninges and spinal ganglia and dissociated as for cerebellum, yielding single cell suspensions of similarly high viabilities.

Cerebellar or spinal cord cells were added to monolayer cultures by diluting $50 \mu \mathrm{l}$ of a cell suspension containing $5,000,25,000,50,000,100,000$, or 250,000 cells into the $0.5 \mathrm{ml}$ of medium in each tissue culture well in which support monolayers were already growing on coverslips, 
and then gently shaking the cultures several times to disperse the added cells evenly. Coverslips occupied $72 \%$ of the surface area in the wells.

Immunofluorescence and identification of neurons. Two fluorochrome indirect immunofluorescence assays with cell type-specific antibodies were carried out as described elsewhere (Raff et al., 1979). To visualize neurons, cultures on glass coverslips were fixed in methanol or $95 \%$ ethanol: $5 \%$ acetic acid at $-20^{\circ} \mathrm{C}$ for $10 \mathrm{~min}$, washed with MEM-H $+5 \%$ FCS, incubated for 25 min $\left(18^{\circ} \mathrm{C}\right)$ with mouse monoclonal antineurofilament (NF) antibody (RT97 ascites, 1:100) (Wood and Anderton, 1981), washed, and labeled for $25 \min \left(18^{\circ} \mathrm{C}\right)$ with rhodamineconjugated goat anti-mouse Ig (G anti-MIg-Rd; Cappell, 1:100), and washed a final time. Astrocytes were identified in fixed cultures using rabbit anti-GFAP antiserum (1:1000), followed by fluorescein-conjugated sheep antirabbit Ig (Sh anti-RIg-Fl; Wellcome, 1:100). Oligodendrocytes were visualized by incubating living cultures with mouse monoclonal antigalactocerebroside (GalC) antiserum (1:20) (Raff et al., 1978b; Ranscht et al. 1982) followed by $G$ anti-MIg-Rd. Mouse monoclonal antiRAN-2 antibody (Bartlett et al., 1981) was used to label ependymal cells, type I astrocytes and their precursors, and meningeal cells. All anti-MIg, and anti-RIg conjugates were adsorbed with $\mathrm{RIg}$ or $\mathrm{MIg}$, respectively, to eliminate cross-reacting antibodies. Living cultures were fixed in methanol or $95 \%$ ethanol:5\% acetic acid after labeling and were mounted in glycerol or Gelvatol (Monsanto). The cells were viewed on a Zeiss Universal microscope equipped with phase contrast, epifluorescence, and rhodamine and fluorescein optics.

Aggregates (defined as two or more neuronal cell bodies in direct contact) and fascicles were clearly distinguishable by light microscopy. Due to the bundling together of neurites emerging from aggregates, it was often difficult to identify unambiguously particular cells as neurons, although in some favorable two- to three-cell aggregates it was, in fact, possible to see that each cell possessed an $\mathrm{NF}^{+}$process. However, when cerebellar cells were grown on monolayers of purified astrocytes, all of the small round or ovoid cells found possessed $\mathrm{NF}^{+}$ processes and $\mathrm{NF}^{+}$cell bodies; no similar cells were found on glial or nonglial monolayers unless CNS neurons were added to the cultures. Moreover, cerebella were used at a stage (P7) when most of the cells present are either neurons or neuronal precursors. Thus, for purposes of quantifying aggregation phenomena we defined "putative neurons" in cerebellar cultures as cells with small $(<10$ $\mu \mathrm{m}$ diameter) round or ovoid $\mathrm{NF}^{+}$cell bodies. The similar numbers obtained in counting total neurons $24 \mathrm{hr}$ after plating onto the different monolayers (Table I) suggest that these criteria were correct.

Scanning electron microscopy. Twenty-four and $48 \mathrm{hr}$ after plating of cerebellar neurons onto astrocyte monolayers, cultures were fixed in $2 \%$ glutaraldehyde in phosphate-buffered saline (PBS) $\left(20^{\circ} \mathrm{C}, 2 \mathrm{hr}\right)$, washed twice with PBS, and then dehydrated by successive 10-min incubations in $50 \%, 70 \%, 90 \%$, and $100 \%$ ethanol. The fixed cultures on coverslips were critical point dried with liquid $\mathrm{CO}_{2}$, sputter-coated with gold, and viewed with a
JEOL JEM 35 scanning electron microscope at an accelerating voltage of $20 \mathrm{kV}$.

Conditioned medium experiments. Astrocytes, fibroblasts, cardiac cells, or meningeal cells were plated onto polylysin-coated (collagen coated for cardiac cells) 60$\mathrm{mm}$ tissue culture wells at either 400,000 cells/well or one heart/three wells. Cultures were grown to confluence, irradiated, and fed with fresh medium. $\Lambda$ fter 1 to 2 days to allow conditioning of the medium, one coverslip of astrocytes was placed into each $60-\mathrm{mm}$ well of the nonglial cell types, or one coverslip of nonglial cells was placed into a $60-\mathrm{mm}$ well of astrocytes. After an additional 4 to $24 \mathrm{hr}$, suspensions of cerebellar and spinal cord cells were plated at a range of densities into each of the various wells, allowed to grow for 24 to $72 \mathrm{hr}$, removed, and assayed by indirect immunofluorescence. In addition, cultures were monitored daily by visual inspection.

Fixation and heat killing of support monolayers. Monolayers of astrocytes or fibroblasts were variously fixed with methanol $\left(-20^{\circ} \mathrm{C}, 5 \mathrm{~min}\right) ; 95 \%$ ethanol:5\% acetic acid $\left(-20^{\circ} \mathrm{C}, 15 \mathrm{~min}\right) ; 1 \%, 2 \%$, or $4 \%$ paraformaldehyde; $1 \%, 2 \%$, or $4 \%$ formalin $\left(20^{\circ} \mathrm{C}, 15 \mathrm{~min}\right)$; or $0.5 \%$ glutaraldehyde $\left(20^{\circ} \mathrm{C}, 15 \mathrm{~min}\right)$. Paraformaldehyde, formalin, and glutaraldehyde were all diluted in phosphate-buffered physiological saline (PBS). After fixation, monolayers were extensively washed in PBS and then left in PBS overnight prior to use.

Astrocyte, fibroblast, and meningeal cultures were heat killed by incubation in culture medium at $60^{\circ} \mathrm{C}$ for 45 min. These monolayers were washed once with fresh medium prior to use. We found that heat-killed monolayers on glass degenerated rapidly following plating of fresh cells. However, when monolayers were grown on tissue culture-treated plastic coverslips (Thermolux), they were stable for at least several days following heat killing and plating of neuronal cultures.

\section{Results}

Astrocytes and nonglia differ markedly in their effects on neuronal growth. Growth of neurons on astrocyte monolayers was characterized by high plating efficiencies, rapid neurite outgrowth, good long-term survival, and maintenance of neuronal cell bodies and processes as separate, unaggregated units. When dissociated cells from cerebellum or spinal cord were plated on astrocytes at densities ranging from 1 to 20 cells $/ 150,000 \mu \mathrm{m}^{2}$ and were visualized after 24 to $72 \mathrm{hr}$ with antineurofilament (NF) antibody (Wood and Anderton, 1981), 30 to $50 \%$ of the initial number of total cerebellar or 20 to $45 \%$ of the initial number of total spinal cord cells had extended $\mathrm{NF}^{+}$processes. Process extension was rapid, and growth cones could be seen within $1 \mathrm{hr}$ postplating. Neuronal cultures could be routinely maintained for 2 weeks or more; in the case of spinal cord, in cultures grown in serum-free defined medium (Bottenstein and Sato, 1979) neurons survived up to 2 months (J. Cohen and J. FokSeang, unpublished observations).

The most striking characteristic of neuronal growth on astrocytes was that at all times both neuronal cell bodies and processes generally remained as integral 
units. With plating densities ranging from 1 to 100 cells/ $150,000 \mu \mathrm{m}^{2}$, we saw only minor aggregation of neuronal cell bodies and no formation of large (i.e., $>$ four neurons) multineuronal aggregates (Figs. 1, 2, 5, and 6 and Table I). Similarly, neurites generally grew as individual processes. Although neurites frequently crossed over each other and pairs of neurites sometimes ran in parallel for short distances (Fig. $2 B$ ), neurites did not bundle together into fascicles (Figs. $1 B$ and 2). This pattern of outgrowth of the neurites to the astrocyte surface was stronger than to other neurites. This pattern of growth was unchanged for as long as cultures were maintained. Finally, when nonconfluent cultures of astrocytes were used as a substrate, neurites growing on the astrocytes rarely strayed off the astrocyte surface to grow on the poly-L-lysine-coated glass.

The growth of CNS neurons plated on monolayers of nonglia differed from the pattern of growth seen on astrocytes in several ways. On nonglia, the majority of cerebellar neurons aggregated together within $24 \mathrm{hr}$ (Fig. 3 , Table I). Cell aggregation and neurite fasciculation were the dominant form of growth on monolayers of nonglia even in the lowest density platings, where aggregates often contained only two to four cells (Table I).

Identification of neurons in aggregates was more difficult in spinal cord cultures than in cerebellar cultures.
Nonetheless, it was clear that aggregation and fasciculation dominated the pattern of spinal neuron growth on nonglia.

Cultures of CNS neurons plated on nonglia differed in two other important respects from those on astrocytes. First, the extent of neurite outgrowth measured after 24 $\mathrm{hr}$ was substantially reduced on the nonglia (Table II). In both cerebellar and spinal cord cultures, average neurite length after $24 \mathrm{hr}$ was significantly greater on astrocytes than on the nonglia. Spinal cord neurons differed from cerebellar neurons in that neurite extension was greater on heart cultures than on fibroblasts, but growth of spinal neurons on heart cells still did not approach the levels of growth on astrocytes. Second, long-term survival was poorer on the nonglia. We could not distinguish whether this was a result of retraction of neurites into the multicellular aggregates or due to cell death; however, it was clear that within a week after plating neurons were rarely found on the nonglial monolayers.

Aggregation and fasciculation do not require glia. The formation of aggregates and fascicles on nonglia could have been due to direct interactions between the CNS neurons or, alternatively, could have been mediated by the small numbers of CNS glia contained within our cell suspensions. To distinguish these possibilities, we plated cell suspensions of $\mathrm{P} 7$ cerebellum, a stage where $<6 \%$ of
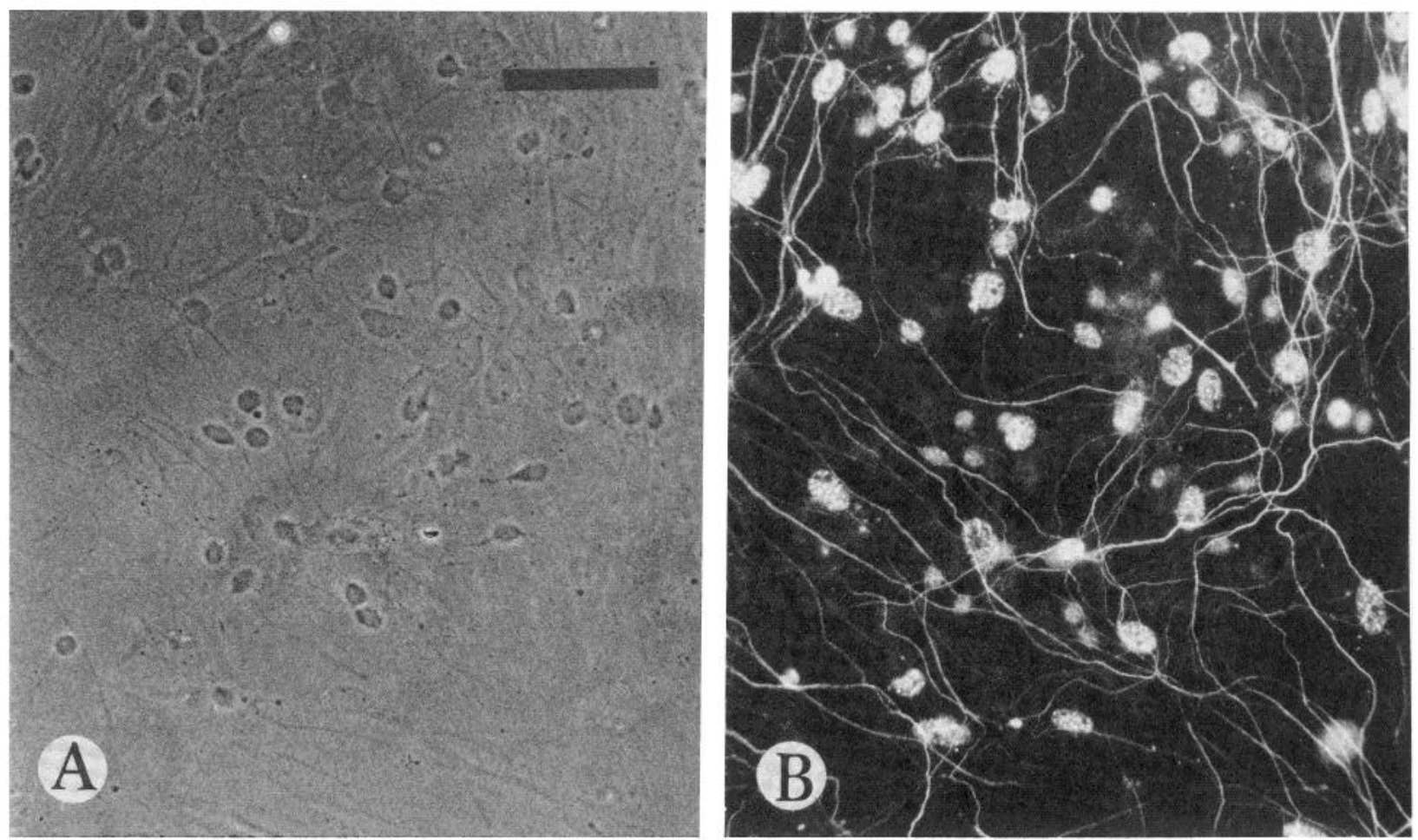

Figure 1. Neurons grown on astrocyte monolayers do not aggregate, and neurites do not fasciculate. One hundred thousand cerebellar neurons were plated onto monolayers of cortical astrocytes grown on glass coverslips. These photomicrographs were taken after 2 days; however, the pattern of growth was identical at all times postplating. $A$, Phase contrast; neuronal cell bodies have remained as single cells. Bar $=50 \mu \mathrm{m}$. $B$, Immunofluorescence view of $A$; neurites were labeled with monoclonal antineurofilament antibody followed by G anti-MIg Rd. Although the neurites cross paths and sometimes run in parallel arrays, they show little or no tendency to form fascicles (see also Fig. 2). Labeling of nuclei is due to cross-reaction of the anti-NF with histones present in the nuclei of all cell types (J. N. Wood, N. Lathangue, D. R. McLachlan, B. J. Smith, B. H. Anderton, and A. Dowling, submitted for publication). 
the cells are $\mathrm{GFAP}^{+}$glia (Cohen et al., 1979; Raff et al., 1983), onto nonglial monolayers and subsequently labeled cultures with a variety of antibodies to identify both neurons and non-neurons.

In low density cultures, where many aggregates contained only two or three cells, we found that 60 to $70 \%$ of the aggregates contained no identifiable glial cells (Table I, Fig. 3). Even in aggregates composed of 10 to 20 cells, the majority of aggregates and associated fascicles contained no cells positive for GFAP, GalC, or RAN2 (Fig. 3). Similar results were obtained for spinal cord; however, we were unable to recognize contaminating Schwann cells in the spinal cord preparations. Therefore, quantitation of glia-free aggregation in these cultures was less reliable. Most of those neurons which grew successfully as single neurons on the nonglia were also not in contact with glial cells, indicating that neurons were able to survive for at least short periods on the nonglial monolayers in the absence of physical contact of the neurons with glial cells.

Schwann cells and astrocytes offer similar substrates for growth of CNS neurons. To determine whether the characteristic effects of astrocytes on growth of CNS neurons reflected properties expressed by other glia, we examined growth of cerebellar neurons on monolayer cultures highly enriched in Schwann cells. The pattern of growth
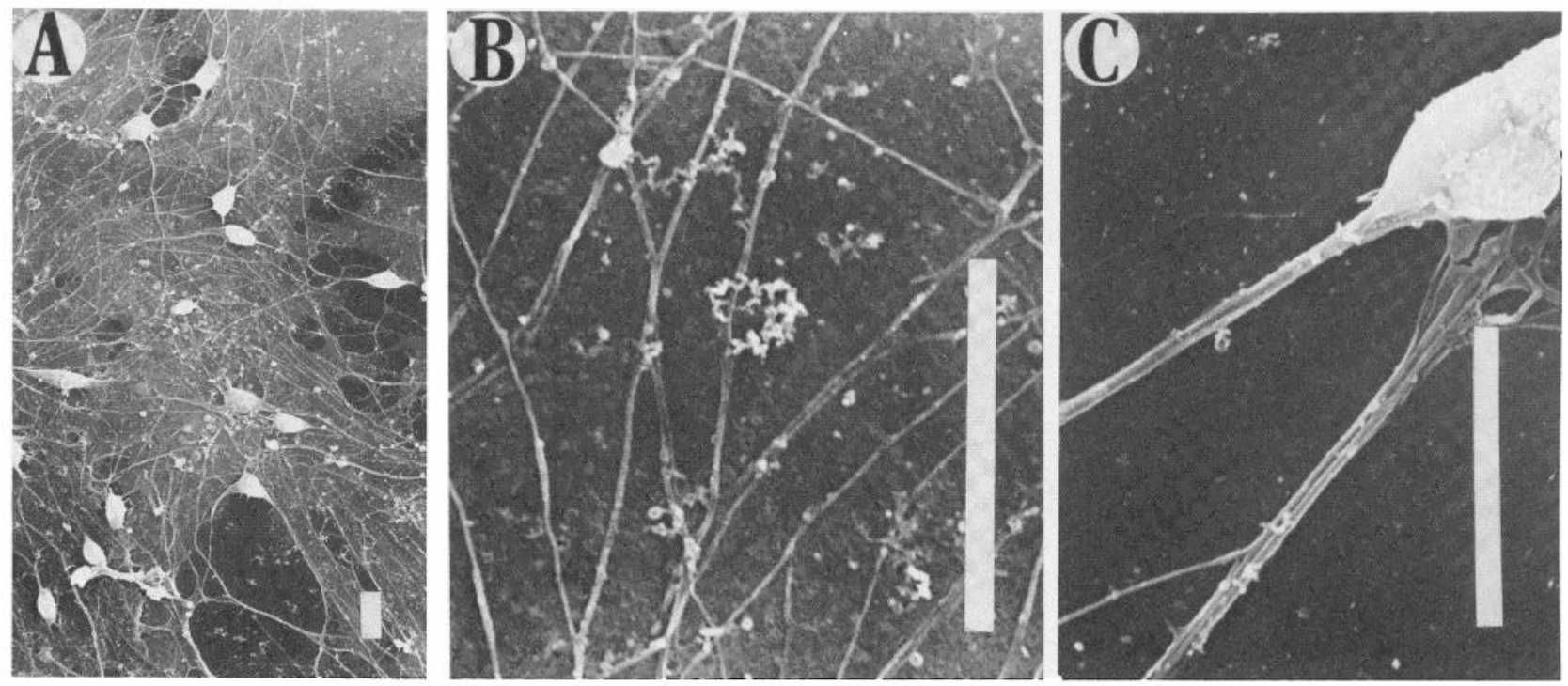

Figure 2. Scanning electron micrograph of neuronal growth on astrocyte monolayers. Fifty thousand cerebellar neurons were plated onto monolayers of cortical astrocytes. After $24 \mathrm{hr}$, cultures were prepared as described under "Materials and Methods." $A$, Single neurites are seen emerging from neuronal cell bodies and extensively crossing over each other. $B$, Higher magnification shows that the majority of these neurites are single processes or, occasionally, pairs of neurites running together for short distances. For comparison, two fascicles are shown in $C$. The lower fascicle contains four to six neurites, and the upper fascicle contains processes from at least two of the cells in the small aggregate. $B a r=10 \mu \mathrm{m}$.

TABLE I

Aggregation of cerebellar neurons on glia and nonglia

Five thousand cerebellar cells were plated in $0.5 \mathrm{ml}$ of medium onto coverslips of confluent astrocytes, fibroblasts, or heart muscle-fibroblast cultures. After $24 \mathrm{hr}$, some cultures were fixed with methanol and labeled with mouse antineurofilament (NF) antibody and rabbit antiglial fibrillary acidic protein (GFAP) antiserum followed by, respectively, rhodamine- and fluorescein-conjugated second layers, which were speciesspecific (see "Materials and Methods"). Alternatively, cultures were fixed with $2 \%$ paraformaldehyde and labeled with mouse antigalactocerebroside $(\mathrm{GalC})$ or anti-RAN-2 antibodies and G anti-MIg-Rd, followed by methanol fixation and labeling with mouse anti-GFAP and Sh anti-RIgFl. Only neurons on fibroblasts were examined with anti-RAN-2, as this antibody also labels heart cells (M. Noble, unpublished observations). In the absence of anti-NF labeling, aggregates were identified by visual inspection. "Putative neurons" were identified as described under "Materials and Methods." Single neurons all had $\mathrm{NF}^{+}$processes and had no cell body contact with other neurons. The proportions of aggregates containing $\mathrm{GalC}^{+}, \mathrm{GFAP}^{+}$(and for fibroblasts, RAN-2 ${ }^{+}$, GFAP) cells were added together to give the maximum proportion of aggregates containing glial cells. The numbers given are averages for three or more separate experiments. Values are mean $\pm \mathrm{SEM}$.

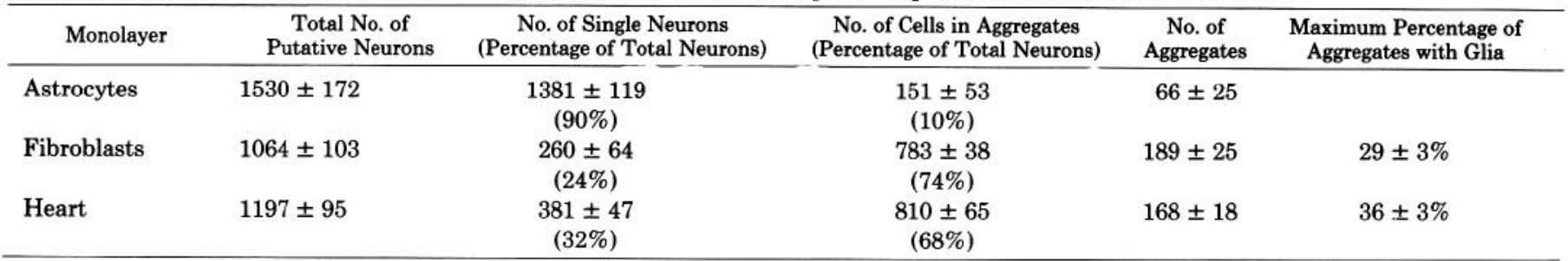



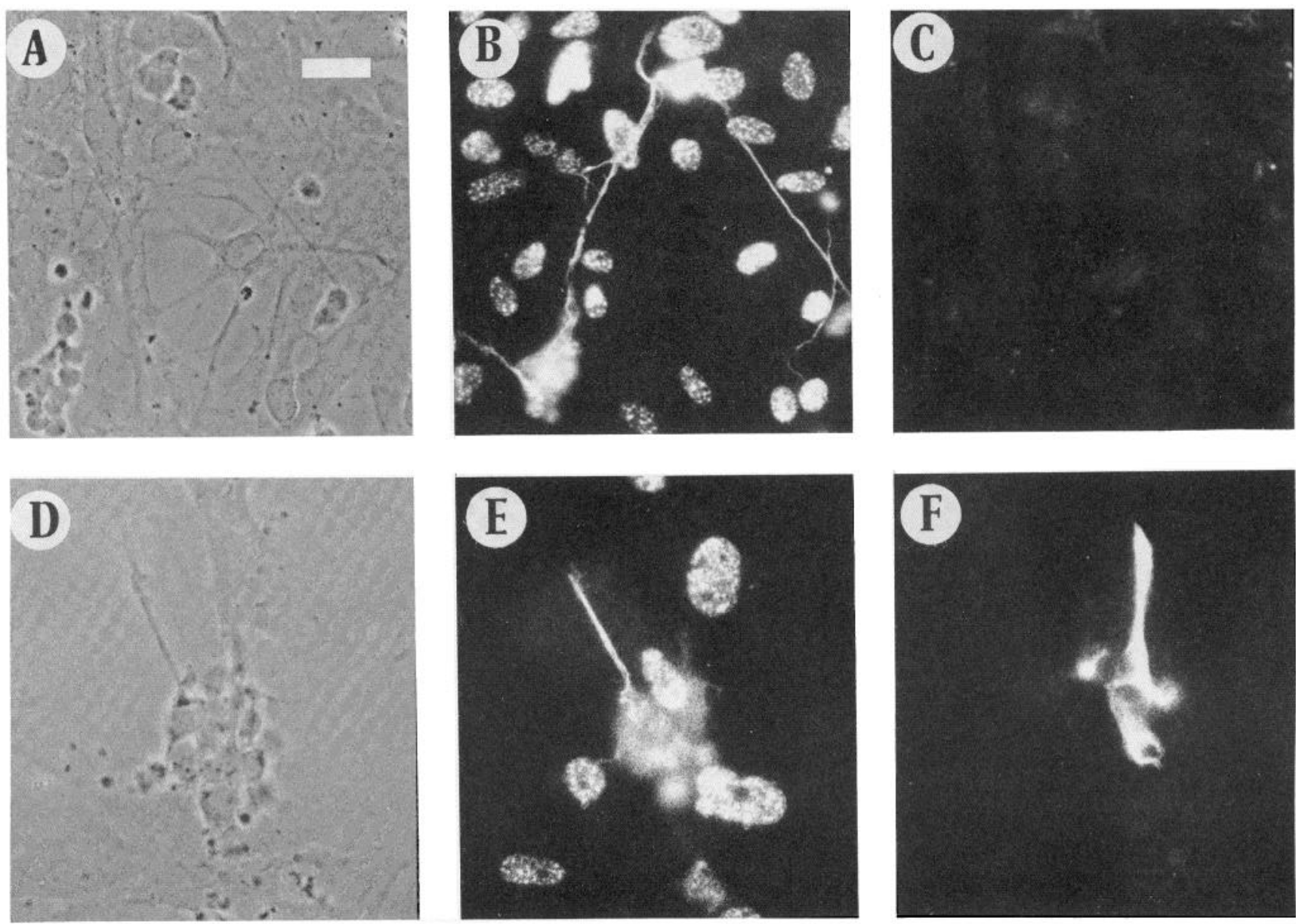

Figure 3. Aggregation and fasciculation do not require glia. Twenty-five thousand cerebellar cells were plated onto monolayers of astrocyte-free meningeal cells. After $24 \mathrm{hr}$, cultures were fixed and labeled with anti-NF to visualize neurons and anti-GFAP to visualize astrocytes (see "Materials and Methods"). $A$ to $C$ shows three aggregates joined by two fascicles, with no astrocytes present in any of these groups. $A$, Phase; $B$, anti-NF; $C$, anti-GFAP. $D$ to $F$ shows a single aggregate associated with a GFAP ${ }^{+}$ astrocyte. $D$, Phase; $E$, anti-NF; $F$, anti-GFAP. Bar $=50 \mu \mathrm{m}$.

of cerebellar neurons plated on Schwann cells proved to be similar to the pattern seen on astrocytes. Regardless of the plating density used, neuronal cell bodies were found as integral units. Neurites generally grew in unfasciculated patterns as seen on astrocytes (Fig. 4), although the Schwann cell processes often seemed to channel neurites into small fascicles, which then dispersed into neurites upon reaching larger expanses of Schwann cell surface. Measurement of neurite length was prevented by the nature of cerebellar neurite outgrowth on Schwann cells, which was characterized by contorted paths around the surface of the cylindrical Schwann cells.

The morphology of neuronal growth was determined by cell surface interactions. The different patterns of growth of CNS neurons on glia and nonglia could have been due to interactions at the cell surface, to astrocytic secretion of substances which might nonspecifically increase neuronal adherence to any substrate, or to secretion by nonglia of substances which might nonspecifically inhibit adherence to any substrate. To distinguish between these possibilities, we grew astrocyte and nonglial monolayers on glass coverslips in medium conditioned by a large

\section{TABLE II}

Neurite extension on glial and nonglial monolayers

Five thousand cerebellar or spinal cord cells were plated in $0.5 \mathrm{ml}$ of medium onto coverslips of confluent astrocytes, fibroblasts, or heart muscle-fibroblast cultures. Cultures were fixed $24 \mathrm{hr}$ after plating and labeled with antineurofilament (NF) antibody and conjugate. All $\mathrm{NF}^{+}$ processes growing from randomly chosen isolated neurons were measured with a graticue. Spinal cord neurons were scored both for the average length of all neurites and also for the average length of the single longest neurite/neuron. Figures are from 100 or more cells, pooled from three or more separate experiments. Values are mean \pm SEM.

\begin{tabular}{|c|c|c|c|}
\hline \multirow{2}{*}{$\begin{array}{l}\text { Source of } \\
\text { Neurons }\end{array}$} & \multicolumn{3}{|c|}{ Substrate } \\
\hline & Astrocytes & Fibroblasts & Heart \\
\hline & \multicolumn{3}{|c|}{$\begin{array}{l}\text { Growth in } \mu \mathrm{m} \text { over } 24 \mathrm{hr}(\% \text { of } \\
\text { growth seen on astroctyes) }\end{array}$} \\
\hline Cerebellum & $\begin{array}{c}146.8 \pm 12.6 \\
(100 \%)\end{array}$ & $\begin{array}{c}65.9 \pm 8.2 \\
(45 \%)\end{array}$ & $\begin{array}{c}67.3 \pm 9.5 \\
(46 \%)\end{array}$ \\
\hline $\begin{array}{l}\text { Spinal cord (all neu- } \\
\text { rites included) }\end{array}$ & $\begin{array}{c}116.9 \pm 16.6 \\
(100 \%)\end{array}$ & $\begin{array}{c}30.2 \pm 3.1 \\
(26 \%)\end{array}$ & $\begin{array}{r}48.7 \pm 4.7 \\
(42 \%)\end{array}$ \\
\hline $\begin{array}{l}\text { Spinal cord (single } \\
\text { longest neurite/ } \\
\text { cell) }\end{array}$ & $\begin{array}{c}190.6 \pm 32.2 \\
(100 \%)\end{array}$ & $\begin{array}{l}40.2 \pm 4.9 \\
\quad(21 \%)\end{array}$ & $\begin{array}{c}69.2 \pm 9.5 \\
(36 \%)\end{array}$ \\
\hline
\end{tabular}



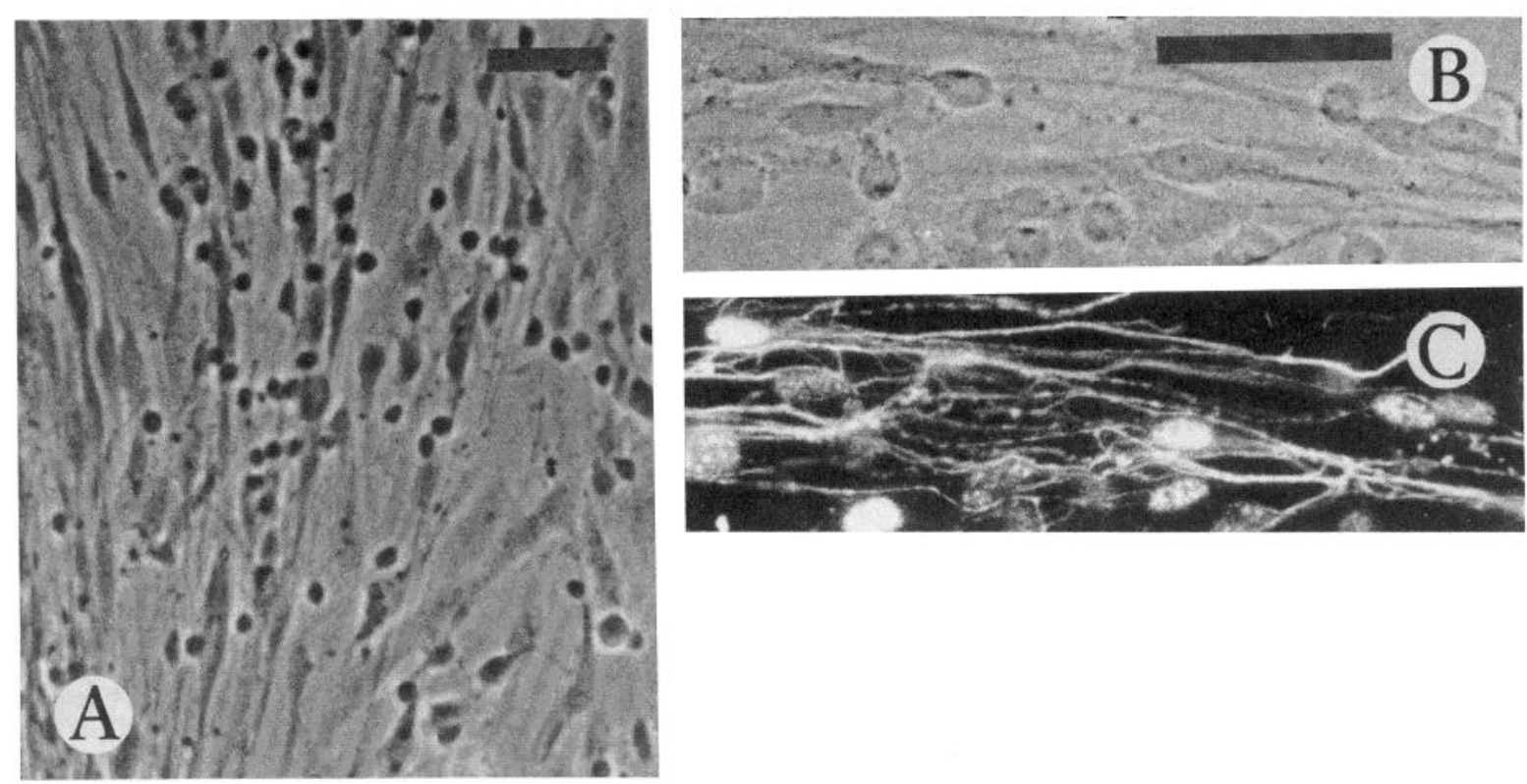

Figure 4. Cerebellar neurons grown on Schwann cells do not aggregate or fasciculate. One hundred thousand cerebellar cells were plated onto cultures of enriched Schwann cells growing on glass coverslips. Cultures were fixed, stained, and photographed at $48 \mathrm{hr}$ postplating. $A$, Cerebellar cells (the small round cells) did not aggregate into the balls of cells typical of growth on nonglia (Fig. 3). Bar $=50 \mu \mathrm{m}$. Similarly, neuritic growth patterns were similar to those seen on astrocytes. $B$, Phase contrast of Schwann cells. Bar $=50 \mu \mathrm{m}$. C , Visualization of neurites in $B$ with anti-NF.

excess of co-cultured nonglia or astrocytes, respectively (Fig. 5). We then plated cerebellar or spinal cord cells onto these cultures and examined the morphology of neuronal growth. In all cases, the pattern of neuronal growth was determined by the type of monolayer with which the neurons were in contact and not by the source of the conditioned medium (Fig. 5). Thus, aggregates and fascicles formed on nonglia, even in the continual presence of astrocyte-conditioned medium; conversely, neither aggregation nor fasciculation was seen in neurons growing on astrocytes, despite their being bathed in medium conditioned by nonglia. Thus, the factors controlling neuronal growth on these cellular substrates seemed to be due to interactions between the respective cell surfaces.

The strictly local nature of the glial and nonglial influences was also seen when cerebellar neurons were plated onto primary cultures of meninges, which contained up to $20 \% \mathrm{GFAP}^{+}$cells. Neurons on the GFAP $^{-}$ cells aggregated, and neurites grew out as fascicles, as in Figure 3 . Neurons on the $\mathrm{GFAP}^{+}$cells grew as they did on the purified astrocytes (Fig. 6). Moreover, as shown in Figure 6, neurites on the GFAP $^{+}$cells often appeared to be constrained in their growth to the astrocyte surface.

Heat-killed astrocyte monolayers function similarly to living astrocytes. To determine whether cell surface interactions between neurons and astrocytes required living astrocytes, monolayers of astrocytes were fixed in a variety of ways (see "Materials and Methods") prior to plating of suspensions of cerebellar or spinal cord cells. All chemical fixation procedures tested destroyed the ability of the astrocyte monolayers to support nonaggregated nonfasciculated neuronal growth. However, astrocytes killed by heating $\left(60^{\circ} \mathrm{C}, 45 \mathrm{~min}\right)$ offered similar surface properties to living astrocytes, in that cerebellar and spinal cord neurons attached and grew as integral units (Fig. 7). Similarly, growth of neurons on heat-killed meninges and fibroblast monolayers was indistinguishable from growth on living meninges and fibroblast monolayers.

\section{Discussion}

Anatomical studies have indicated a number of instances where glia seem to function as substrate pathways during CNS development. The astrocyte-related radial glia (Schmechel and Rakic, 1979) are present in all brain regions during the peak of neuronal cell body migration (Levitt and Rakic, 1980), and these glial cells appear to offer the only class of cellular process with which migrating neurons are associated throughout the course of migration (Schmechel and Rakic, 1979). The importance of glia-like cells in guiding axonal growth in the CNS has been elegantly demonstrated in studies on corpus callosum development, where Silver and colleagues (1982) have identified a "glial sling" which appears to play an essential role in guiding the pioneer fibers of the corpus callosum across the midline during embryonic development. However, despite these indications that glial surface properties might be of considerable importance during development, in vitro studies of glia-neuron interactions have focused predominantly on diffusible factors produced by glia (see, e.g., Varon and Adler, 1981). Those few studies which have looked at cell surface interactions have generally been limited to cells of the PNS and/or have used either heterogeneous or uncharacterized cell populations (Guillery et al., 1970; Luduena, 1973; Sensenbrenner and Mandel, 1974; Varon, 

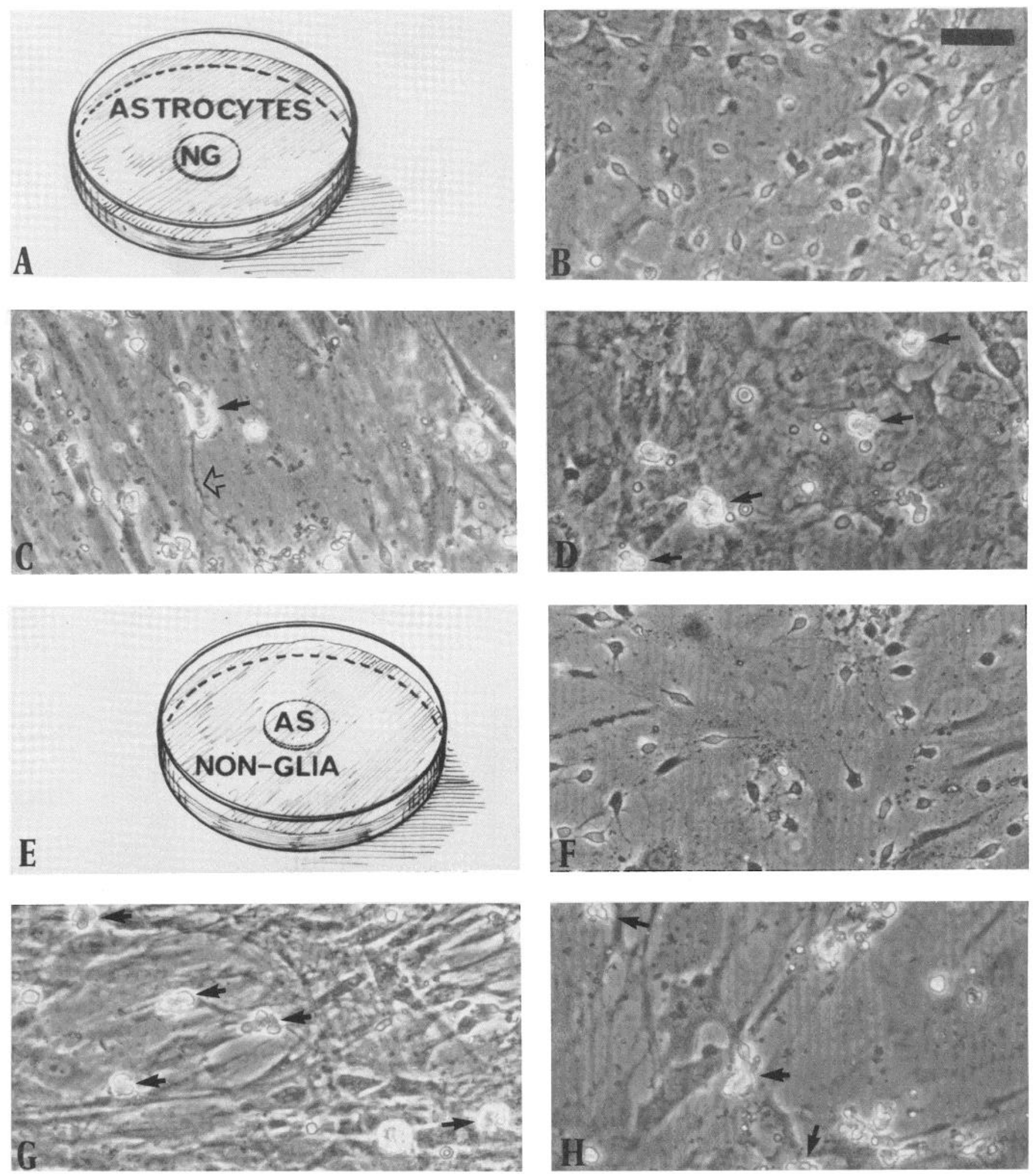

Figure 5. The pattern of neuronal growth is determined by cell surface interactions. $A$ to $D$, Coverslips with monolayers of nonglial cells were placed into $60-\mathrm{mm}$ wells containing cultures of astrocytes. After 4 to $24 \mathrm{hr}, 5 \times 10^{5}$ cerebellar cells were added to the Petri dishes. Cultures were photographed after an additional $24 \mathrm{hr}$. Despite being bathed in medium conditioned by astrocytes, neurons on the nonglial monolayers grew in aggregates (solid arrows) and fascicles (hollow arrow). $B, A$ strocytes. $C$, Astrocyte-free meninges. $D$, Fibroblasts. Cerebellar cells plated into cultures containing coverslips of astrocytes grown in medium conditioned by nonglia gave similar results. $F$, Astrocytes in meninges-conditioned medium; identical cultures were seen with fibroblast-conditioned medium. $G$, Astrocyte-free meninges. $H$, Fibroblasts. Bar $=50 \mu \mathrm{m}$. 

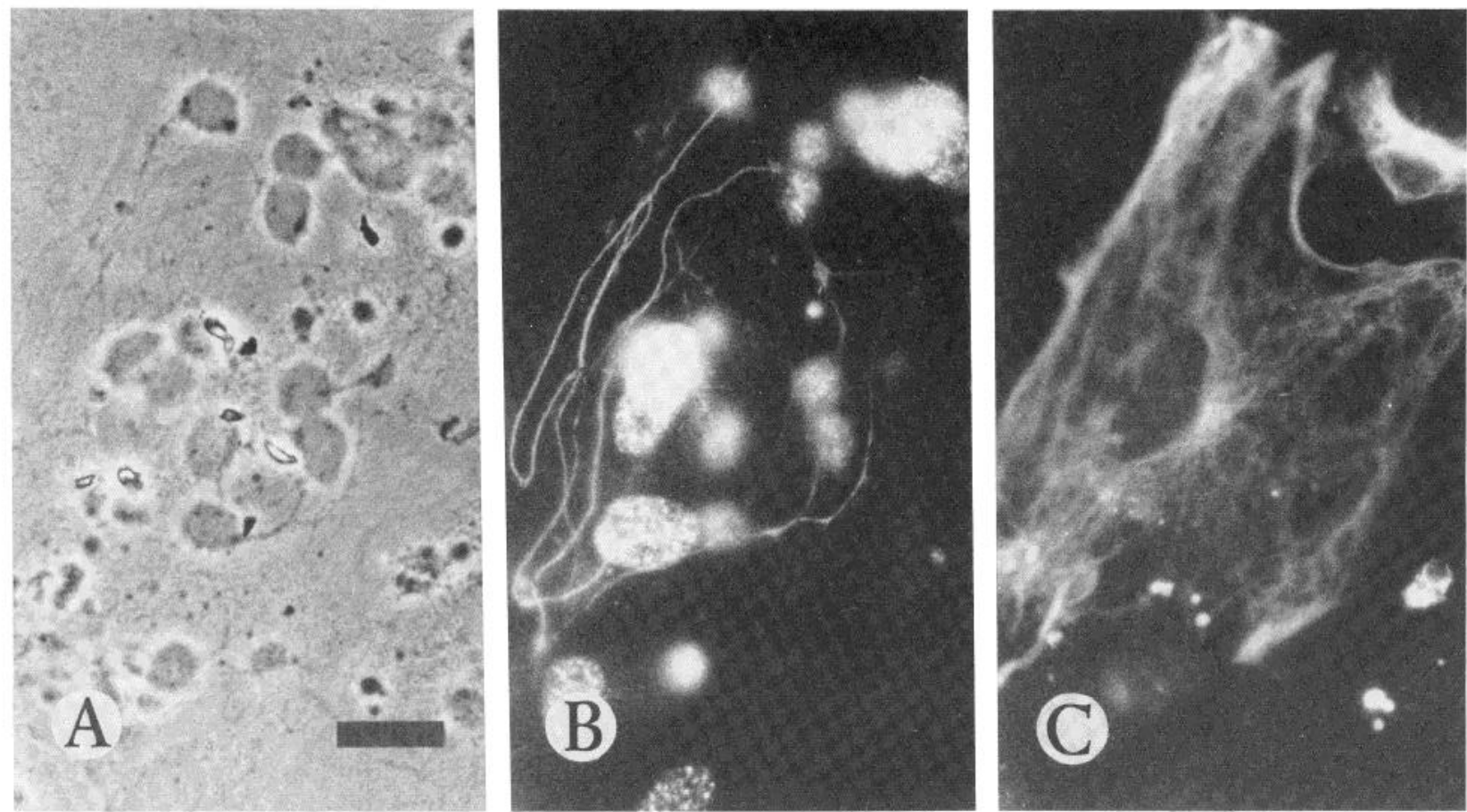

Figure 6. The local nature of cell surface effects on neuronal growth. Twenty-five thousand cerebellar cells were plated onto coverslip cultures of primary meninges, which contained up to $20 \% \mathrm{GFAP}^{+}$cells. In this figure, those cerebellar neurons growing on an isolated astrocyte have not aggregated, and neurites are not fasciculated. Neurite growth appears to be constrained to the astrocyte surface. $A$, Phase; $B$, anti-NF; $C$, anti-GFAP. Bar $=25 \mu \mathrm{m}$.

1975; Wessels et al., 1980; Adler and Varon, 1981). Nonetheless, these studies have indicated that neurons grown in vitro exhibit a preference for growth on some nonneuronal cells.

In our studies, we have examined the consequences of surface interactions with identified glia and nonglia on the in vitro growth of CNS neurons. By using cell typespecific antibodies we have been able to reliably identify cells of interest so as to investigate these interactions more accurately than would be possible without the use of such markers. The glial populations used were highly enriched astrocytes from cerebral cortex and highly enriched Schwann cells from sciatic nerve; the nonglia were skin fibroblasts, mixed cardiac muscle-fibroblast cultures, and astrocyte-free meningeal cells. The neurons have primarily been cerebellar neurons, which are confined to the CNS in their growth, and spinal cord neurons, at least some of which extend processes both centrally and peripherally. As cytosine arabinoside (AraC) was used in the preparation of glial cells but not of nonglia, we have confirmed that secondary astrocytes prepared without AraC treatment (which contain 10 to $15 \% \mathrm{GFAP}^{-}$fibroblast-like cells) function similarly to the more highly enriched AraC-treated astrocytes (unpublished observations). We have also confirmed our observations with CNS neurons from retina, hippocampus, and caudate (unpublished observations). Our results indicate that $(a)$ astrocytes and Schwann cells display surface properties which can structure the pattern of neuronal growth in vitro and which dramatically distinguish these glial cells from nonglia, and $(b)$ the interaction of axons with the non-neuronal milieu through which they grow may play an important role in regulating fasciculation, a process which has generally been treated as due primarily to axon-axon interactions (e.g., Nakai, 1960; Rutishauser et al., 1978; Scholes, 1979).

Growth on astrocytic monolayers had three effects on the growth of CNS neurons: $(a)$ neurite extension was enhanced as compared with extension on nonglia, $(b)$ neuronal cell bodies generally remained as single unaggregated units, and (c) neurites showed no tendency to form large fascicles, often growing near to and crossing over each other but almost always behaving as though their preferred attachment was to the glial surface rather than to other neurites.

In contrast, when CNS neurons were plated on nonglial cells, neurite outgrowth was substantially reduced, multineuronal aggregates formed rapidly, and neurites were found primarily in fascicles. Aggregation and fasciculation seemed to be due to direct interactions between neurons, in that the presence of CNS glia as a binding substrate was not required for either cell body aggregation or fasciculation; this was seen most clearly when low-density platings of cerebellum (i.e., $<1$ cell/ $150,000 \mu \mathrm{m}^{2}$ ) were used.

The influence of glia and nonglia on the morphology of neuronal growth could theoretically be due either to cell surface interactions or to soluble factors which could cause alterations in neurite adherence to the substrate or to other neurites (e.g., see Schubert and Whitlock, 1977; Collins and Garrett, 1980; Rutishauser and Edelman, 1980; Adler et al., 1981). Two findings indicate that surface interactions could account exclusively for the results obtained in our studies. First, when neurons were 

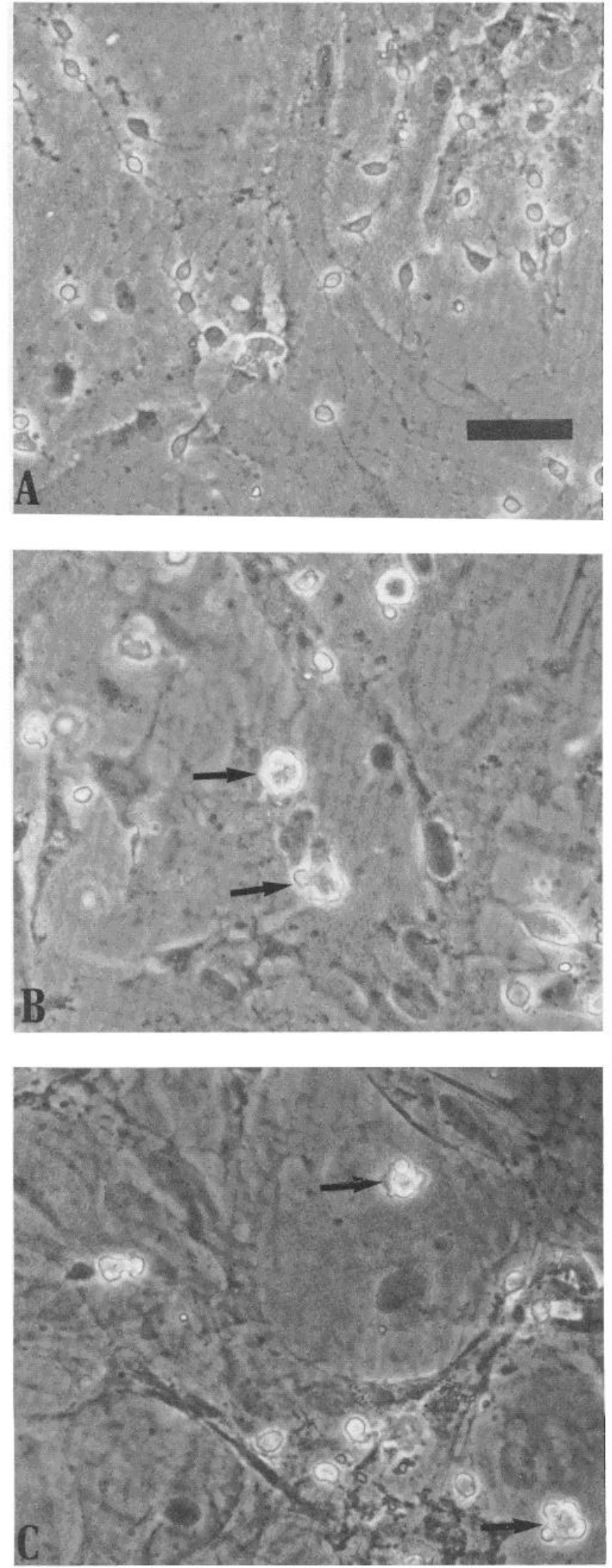

Figure 7. Growth on heat-killed monolayers is similar to growth on living monolayers. Monolayer cultures were heated to $60^{\circ} \mathrm{C}$ for $45 \mathrm{~min}$. Cerebellar cells plated onto these monolay- plated on astrocytes growing in medium conditioned by nonglia or on nonglial cells growing in astrocyte-conditioned medium, the morphology of neuronal growth was characteristic of the monolayer with which the neurons were in contact. Second, neurons grew on heat-killed astrocytes in the same way as on living astrocytes.

Previous work has indicated that both glial and nonglial cells secrete molecules which can promote outgrowth of neurites from a variety of neurons (Collins and Garrett, 1980; Dribin and Barrett, 1980; Adler et al., 1981; Lander et al., 1982; J. R. Fallon, submitted for publication). These neurite-promoting factors are ineffective in promoting outgrowth of CNS neurons (with the exception of spinal cord neurons) and, thus, appear to differ from the astrocyte and Schwann cell surface molecules which promote the extensive and nonfasciculated growth of CNS neurons. Comparison of our present results with this previous work also indicates the very different substrate requirements of PNS versus CNS neurons for the promotion of neurite outgrowth.

The simplest explanation for our observations is that there exist hierarchies of adherence in the nervous system such that CNS neurons are more adherent to astrocytes or Schwann cells than to other neurons but are more adherent to other neurons than to nonglia. Using artificial substrates, it has been shown that when growing neurites are presented with alternative substrates, they grow preferentially on the more adherent of these (Letourneau, 1975a). The observation that neurites growing on a glial surface did not bundle together to form large fascicles, even when growing directly adjacent to each other and repeatedly crossing paths, strongly suggests that glia provide a preferred substrate and that the neurites were more adherent to the underlying glia than to each other. By contrast, the aggregation and fasciculation of neuronal cell bodies and processes on nonglia suggest that, compared with glia or other neurones, the nonglia present a poorly adherent substrate. The reduced neurite extension seen on nonglia supports the view that nonglia present a less adherent surface than glia, since neurite outgrowth on artificial substrates is reduced as the adhesiveness of the substrate declines (Letourneau, $1975 \mathrm{~b})$; studies of the binding of radiolabeled neuroblasts to astrocytes and to nonglia also indicate that neurons are more adherent to glia than to nonglia (Foucaud et al., 1982; J. Cohen and J. Fok-Seang, manuscript in preparation). The possibility that neurons adhere better to glial cells than to each other is notable, since it would seem to be an exception to the general rule that cells are more adherent to like than to nonlike cells (Townes and Holtfreter, 1955; Moscona, 1962). The nonfasciculated zrowth of cerebellar neurons on Schwann cells and the imilarly nonfasciculated growth of PNS neurons on astrocytes (J. R. Fallon, submitted for publication) suggest that this neuron-glial adherence can even supersede tissue-specific (as opposed to cell type-specific) adhesion.

ers grew in the same pattern as cells plated onto living monolayers (compare with Fig. 5). A, Astrocytes. B, Astrocyte-free meningeal cells. $C$, Fibroblasts. Some aggregates are marked with arrows. Bar $=50 \mu \mathrm{m}$. 
The possibility that neurons and axons preferentially adhere to glial surfaces offers a cellular explanation for a number of in vivo observations. For example, during development of the mouse optic nerve, neurites confronted with primitive glia and pigmented epithelial cells in the optic stalk are restricted in their growth to the surface of those cells which go on to become $\mathrm{GFAP}^{+}$glia (Silver and Sapiro, 1981; J. Silver, personal communication). Similarly, during regeneration in the PNS, neurite outgrowth occurs preferentially through the Schwann cell-lined perineurial tubes and not on the nonglial epineurial surface surrounding the empty nerve trunk (Gutmann and Young, 1944).

Our observations lead to the prediction that fasciculation of CNS axons during development will reflect relative availability of glial surfaces. Thus, in the absence of glial surfaces, all growing axons should co-fasciculate together. Such a pattern of growth, where all axons are in one central bundle, is seen in the frog optic nerve trunk, which is composed almost entirely of pigmented epithelial cells during early stages of development (Silver and Sapiro, 1981). In contrast, in mouse and chick optic nerves axon outgrowth occurs in numerous small fascicles all along the surfaces formed by the primitive glia of the optic nerve stalk (Silver and Sapiro, 1981). In the spinal cord, where early axons grow in an unfasciculated manner along glial processes (Holley, 1983), we thus expect that total glial surface area exceeds the surface area occupied by axons.

The generation and maintenance of order within an axon tract could conceivably be due to selective interaxonal adhesion, leading to fasciculation of axons with particular other axons, such as has been described in developing PNS tracts (Roberts and Taylor, 1982; Raper et al., 1983). However, in contrast to development in the PNS, all of the well described cases of orderly development of CNS axon tracts indicate that new axons almost always are added along the edges of fascicles, at the axonglial interface (Scholes, 1979; Bodick and Levinthal, 1980; Nornes et al., 1980; Sapiro et al., 1980; Easter et al., 1981). This pattern of growth, whereby new fibers are added on in a layer between old fibers and the glia limitans, in combination with the sequential generation of, e.g., optic axons (Silver and Sidman, 1980), and sequential interaction with target cells (Lo Presti et al., 1973), would continually maintain topographic precision during development (Silver and Sapiro, 1981). Thus, simply by presenting a preferred adherent substrate for axon outgrowth, the glia could play a major role in organizing the specifically patterned development of CNS axon tracts. It will be of interest to determine whether glia also display regionally specific surface properties, perhaps associated with different substrate pathways (Katz and Lasek, 1981).

It is also worth noting that the use of purified astrocytes as a substrate for neuronal growth represents an uncomplicated means of growing a wide variety of neurons under excellent conditions for electrophysiological studies. Neurite outgrowth begins within $1 \mathrm{hr}$ after plating, and the optics of the culture are such that extracellular recording from processes and growth cones should be feasible. Most importantly, neurons can be grown so sparsely that the properties of single nonsynapsed cells can be investigated; their morphology of growth is such that formation of synapses on their own cell bodies (autosynapses) is unlikely, and high levels of neuronal survival are routinely achieved. Thus, the use of astrocyte monolayers as a standard substrate should also be useful in studying neuronal populations which thus far have proven difficult to grow in dispersed cultures, such as the chemosensory neurons of the olfactory epithelium (Noble et al., 1984.)

\section{References}

Adler, R., and S. Varon (1981) Neuritic guidance by nonneuronal cells of ganglionic origin. Dev. Biol. 86: 69-80.

Adler, R., M. Manthorpe, S. D. Skaper, and S. Varon (1981) Polyornithine-attached neurite-promoting factors (PNPFs). Culture sources and responsive neurons. Brain Res. 206: 129 144.

Bartlett, P. F., M. D. Noble, R. M. Pruss, M. C. Raff, S. Rattray, and C. Williams (1981) Rat neural antigen-2 (Ran2): A cell surface antigen on astrocytes, ependymal cells, Müller cells and leptomeninges defined by a monoclonal antibody. Brain Res. 204: 339-351.

Bignami, A., L. F. Eng, D. Dahl, and C. T. Uyeda (1972) Localization of the glial fibrillary acidic protein in astrocytes by immunofluorescence. Brain Res. 43: 429-435.

Bodick, N., and C. Levinthal (1980) Growing optic nerve fibers follow neighbors during embryogenesis. Proc. Natl. Acad. Sci. U. S. A. 77: 4374-4378.

Bottenstein, J. E., and G. H. Sato (1979) Growth of a rat neuroblastoma cell line in serum-free supplemental medium. Proc. Natl. Acad. Sci. U. S. A. 76: 514-517.

Brockes, J. P., K. L. Fields, and M. C. Raff (1977) A surface antigenic marker for rat Schwann cells. Nature 266: 364366.

Johen, J., P. Woodhams, and R. Balazs (1979) Isolation of an astroglia-enriched fraction from the developing cerebellum. Brain Res. 161: 503-514.

Collins, F., and J. E. Garrett, Jr. (1980) Elongating nerve fibers are guided by a pathway of material released from embryonic non-neuronal cells. Proc. Natl. Acad. Sci. U. S. A. 77: 62266228.

Dribin, L. B., and J. N. Barrett (1980) Conditioned medium enhances neurite outgrowth from rat spinal cord explants. Dev. Biol. 74: 184-195.

Easter, S. S., Jr., A. C. Rusoff, and P. E. Kish (1981) The growth and organization of the optic nerve and tract in juvenile and adult goldfish. J. Neurosci. 1: 793-811.

Foucaud, B., R. Reeh, M. Sensenbrenner, and G. Gombos (1982) Kinetic and morphological analysis of the preferential adhesion of chick embryo neuronal cells to astroglial cells in culture. Exp. Cell Res. 137: 285-294.

Guillery, R. W., H. M. Sobkowicz, and G. L. Scott (1970) Relationships between glial and neuronal elements in the development of long-term cultures of the spinal cord of the fetal mouse. J. Comp., Neurol. 140: 1-34.

Gutmann, E., and J. Z. Young (1944) The re-innervation of muscle after periods of atrophy. J. Anat. 78: 15-43.

Holley, J. (1983) The development of the circumferential axonal pathway. Ph.D. thesis, Case Western Reserve University, Cleveland, $\mathrm{OH}$.

Jorgenson, O. S., A. Delouvee, J. P. Thiery, and G. M. Edelman (1980) Nervous system specific protein-D2 is involved in adhesion among neurites from cultured rat ganglia. FEBS Lett. 111: 39-42.

Katz, M. J., and R. J. Lasek (1981) Substrate pathways demonstrated by transplanted Mauthner axons. J. Comp. Neurol. 195: 627-641. 
Lander, A. D., D. K. Fujii, D. Gospodarowicz, and L. F. Reichardt (1982) Characterization of a factor that promotes neurite outgrowth: Evidence linking activity to a heparan sulfate proteoglycan. J. Cell Biol. 94: 574-585.

Letourneau, P. C. (1975a) Cell-to-substratum adhesion and guidance of axonal elongation. Dev. Biol. 44: 92-101.

Letourneau, P. C. (1975b) Possible roles for cell-to-substratum adhesion in neuronal morphogenesis. Dev. Biol. 44: 77-91.

Levitt, P., and P. Rakic (1980) Immunoperoxidase localization of glial fibrillary acidic protein in radial cells and astrocytes of the developing rhesus monkey brain. J. Comp. Neurol. 193: 815-840.

Lo Presti, V., E. R. Macagno, and C. Levinthal (1973) Structure and development of ncuronal connections in isogenic organisms: Cellular interactions in the development of the optic lamina of Daphnia. Proc. Natl. Acad. Sci. U. S. A. 70: 433437.

Ludueña, M. A. (1973) Nerve cell differentiation in vitro. Dev. Biol. 33: 268-281.

McCarthy, K. D., and J. de Vellis (1980) Preparation of separate astroglial and oligodendroglial cultures from rat cerebral tissue. J. Cell Biol. 85: 890-902.

Moscona, A. A. (1962) Cellular interactions in experimental histogenesis. Int. Rev. Exp. Pathol. 1: 371-529.

Nakai, J. (1960) Studies on the mechanism determining the course of nerve fibers in tissue culture. II. The mechanisms of fasciculation. Z. Zellforsch. Mikrosk. Anat. 52: 427-449.

Noble, M., P. S. Mallaburn, and N. Klein (1984) The growth of olfactory neurons in short term cultures of rat olfactory epithelium. Neurosci. Lett., in press.

Nornes, H. O., H. Hart, and M. Carry (1980) Pattern of development of ascending and descending fibers in embryonic spinal cord of chick. I. Role of position information. J. Comp. Neurol. 192: 119-132.

Raff, M. C., E. Abney, J. P. Brockes, and A Hornby-Smith (1978a) Schwann cell growth factors. Cell 15: 813-822.

Raff, M. C., R. Mirsky, K. L. Fields, R. P. Lisak, S. H. Dorfman, D. H. Silberberg, N. A. Gregson, S. Liebowitz, and M. Kennedy (1978b) Galactocerebroside: A specific cell surface antigenic marker for oligodendrocytes in culture. Nature 274: 813-816.

Raff, M. C., K. L. Fields, S. Hakomori, R. Mirsky, R. M. Pruss, and J. Winter (1979) Cell-type-specific markers for distinguishing and studying neurons and the major classes of glial cells in culture. Brain Res. 174: 283-308.

Raff, M. C., E. R. Abney, J. Cohen, R. Lindsay, and M. Noble (1983) Two types of astrocytes in cultures of developing rat white matter: Differences in morphology, surface gangliosides, and growth characteristics. J. Neurosci. 3: 1289-1300.

Ranscht, B., P. A. Clapshaw, J. Price, M. Noble, and W. Seifert (1982) Development of oligodendrocytes and Schwann cells studied with a monoclonal antibody against galactocerebroside. Proc. Natl. Acad. Sci. U. S. A. 79: 2709-2713.
Raper, J. A., M. Bastiani, and C. S. Goodman (1983) Pathfinding by neuronal growth cones in grasshopper embryos. II. Selective fasciculation onto specific axonal pathways. J. Neurosci. 3: 31-41.

Roberts, A., and J. S. H. Taylor (1982) A scanning electron microscope study of the development of a peripheral sensory neurite network. J. Embryol. Exp. Morphol. 69: 237-250.

Rutishauser, U., and G. M. Edelman (1980) Effect of fasciculation on the outgrowth of neurites from spinal ganglia in culture. J. Cell Biol. 87: 370-378.

Rutishauser, W., W. E. Gall, and G. M. Edelman (1978) Adhesion among neural cells of the chick embryo. IV. Role of the cell surface molecule CAM in the formation of neurite bundles in cultures of spinal ganglia. J. Cell Biol. 79: 382-393.

Sapiro, J. A., J. Silver, and M. Singer (1980) The patterning of optic axons during early development in Xenopus laevis. Invest. Ophthalmol. Vis. Sci. 9: 247.

Schmechel, D. E., and P. Rakic (1979) A Golgi study of radial glial cells in developing monkey telencephalon: Morphogenesis and transformation into astrocytes. Anat. Embryol. 156: $115-152$.

Scholes, J. H. (1979) Nerve fiber topography in the retinal projection to the tectum. Nature 278: 620-625.

Schubert, D., and C. Whitlock (1977) Alterations of cellular adhesion by nerve growth factor. Proc. Natl. Acad. Sci. U. S. A. $74: 4055-4058$.

Sensenbrenner, M., and P. Mandel (1974) Behavior of neuroblasts in the presence of glial cells, fibroblasts and meningeal cells in culture. Exp. Cell Res. 87: 159-167.

Silver, J., and J. Sapiro (1981) Axonal guidance during development of the optic nerve: the role of pigmented epithelia and other extrinsic factors. J. Comp. Neurol. 202: 521-538.

Silver, J., and R. L. Sidman (1980) A mechanism for the guidance and topographic patterning of retinal ganglion cell axons. J. Comp. Neurol. 189: 101-111.

Silver, J., S. E. Lorenz, D. Wahlsten, and J. Coughlin (1982) Axonal guidance during development of the great cerebral commissures: Descriptive and experimental studies, in vivo, on the role of preformed glial pathways. J. Comp. Neurol. 210: 10-29.

Townes, P. L., and J. Holtfreter (1955) Directed movements and selective adhesion of embryonic amphibian cells. J. Exp. Zool. 128: 53-120.

Varon, S. (1975) Neurons and glia in neuronal cultures. Exp. Neurol. 48: 93-134.

Varon, S., and R. Adler (1981) Trophic and specifying factors directed to neuronal cells. Adv. Cell. Neurobiol. 2: 115-163.

Wessels, N. K., P. C. Letourneau, R. P. Nuttall, K. Luduen̂aAnderson, and J. M. Geiduschek (1980) Responses to cell contacts between growth cones, neurites and ganglionic nonneuronal cells. J. Neurocytol. 9: 647-664.

Wood, J. N., and B. Anderton (1981) Monoclonal antibodies to mammalian neurofilaments. Biosci. Rep. 1: 263-268. 